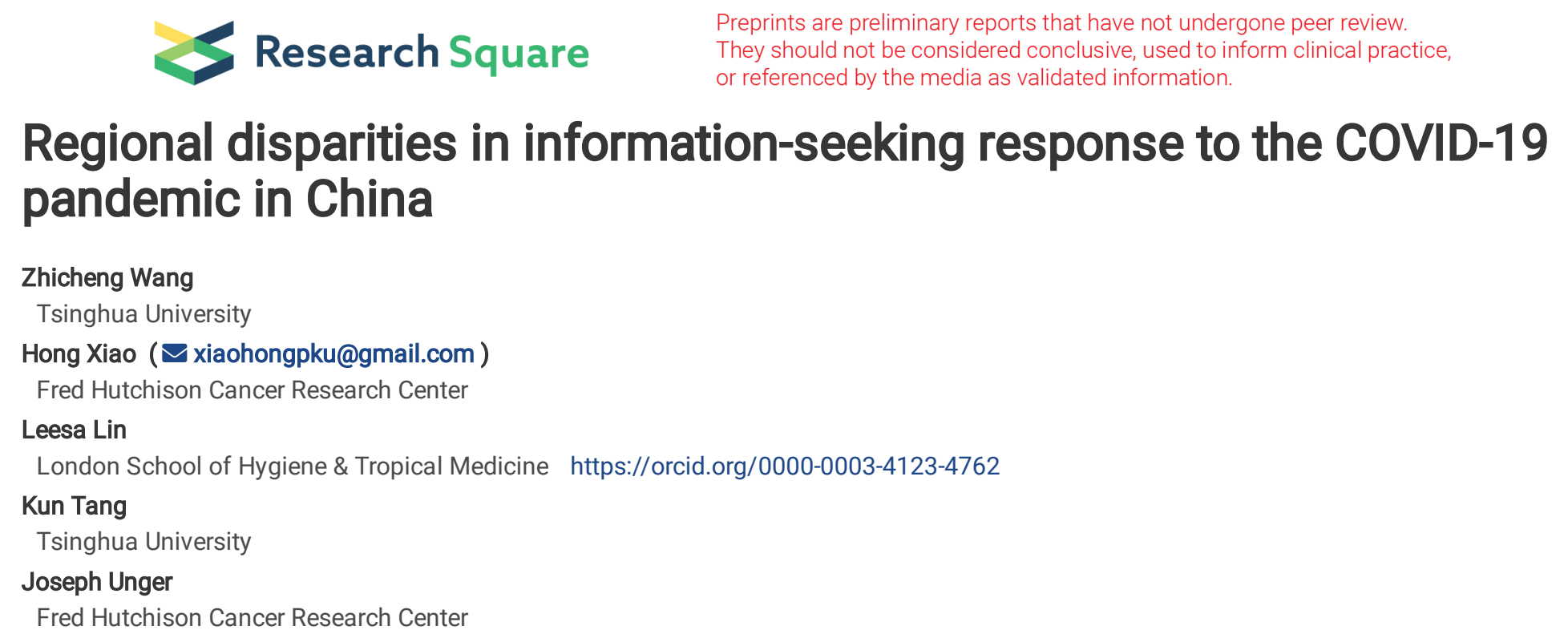

\section{Regional disparities in information-seeking response to the COVID-19 pandemic in China}




\section{Abstract}

The emergence of the COVID-19 virus and the subsequent official announcement of human-to-human transmission of COVID-19 alarmed the public and initiated the uptake of preventive measures. We conducted interrupted time-series analyses using Baidu Search Index from Jan 1 , 2017 to Mar 15, 2021 to investigate how information seeking changed over time and how changes in information seeking varied across regions in China. Our findings show that changes in the patterns of search interest in COVID-19 in each province of China occurred in a synchronous fashion during the first wave of the COVID-19 pandemic and subsequent local outbreaks, irrespective of the location and severity of each outbreak. However, inequalities in the magnitude of public response to and awareness of COVID-19 were evident, with lower-levels of information seeking regarding COVID-19 in less developed areas compared with developed areas.

\section{Introduction}

In late December 2019, a new type of acute respiratory syndrome, which was later known as coronavirus disease-COVID-19, was first reported in Wuhan, China. This unknown coronavirus caused public alarm in Chinese reminiscent of the SARS outbreak in 2003. The subsequent official confirmation of human-to-human transmission of COVID-19 on 20 January 2020 further alarmed the public ${ }^{1}$. The public's informationseeking behaviors in general and in particular as it related to COVID-19 can be captured by the use of data from Internet search engines ${ }^{2}$.

Epidemiological research has shown how the collective attention of the public changed regarding COVID-19 in early 2020. Studies have demonstrated that search volumes for COVID-19 related words increased during the first waves of COVID-19, especially the declaration of a Public Health Emergency of International Concern (PHEIC) by World Health Organization on 12 March 2020, but then fell to normal levels ${ }^{3,4}$. Outside of China, many countries adopted herd immunity policies and mitigation strategies, so the public in these countries may be accultured to COVID-19 cases fluctuation and consider it the norm ${ }^{5,6}$. Search interests for COVID-19 related words fell and then remained at a consistently low level in other countries ${ }^{2-4}$. In contrast, since the first wave of COVID-19 in early 2020, China has taken a "zero tolerance" COVID-19 policy, implementing a series of non-pharmaceutical interventions (NPIs), including contact tracing and isolation, strict border control, massive testing. From 21 Feb to 17 March 2020, the average number of reported daily domestic new COVID-19 cases was under ten, and from 18 Mar to 28 April, there were no additional reported domestic COVID-19 cases ${ }^{1}$. However, subsequent waves of COVID-19 did occur due to slackened quarantines, leading to locally transmitted infections and imported cases domestic COVID-19 spreading ${ }^{1}$. These subsequent domestic COVID-19 outbreaks, though minor, raised alarm with the public. Patterns of information-seeking related to these subsequent outbreaks have yet to be studied.

Previous survey-based studies have shown that individuals with lower socioeconomic status have lower awareness, concern and knowledge about certain infectious disease during the outbreaks ${ }^{7-9}$. Therefore, collective public information-seeking behaviors may vary across the 31 provinces in China in relation to differences in socioeconomic development ${ }^{10}$. However, few studies about inequities in awareness or response to COVID-19 in China have been conducted to date, in part due to the failure to capture the social determinants in the health information system in China. Addressing health inequities against COVID-19 is urgently needed, ${ }^{11}$ since such inequities can exacerbate existing social inequalities ${ }^{12}$. Many adolescents and adults are using the internet to diagnose themselves or learn about health concerns ${ }^{13-16}$; in this scenario, internet access and use becomes an increasingly important vehicle to improve health literacy and potentially health outcomes $^{17-19}$. The number of internet users in China exceeded one billion individuals as of August $2021^{20}$. Thus, public knowledge, awareness of and concerns about COVID-19 can be measured by search interests in COVID-19 related terms. The investigation of the intensity of internet search interests can therefore be used to examine potential differences in patterns of information-seeking reactions (and by extension, health literacy and health outcomes) regarding the pandemic by levels of socioeconomic status 15,18,21,22 .

\section{Results}

Across the 31 provinces and regions in mainland China, the mean daily search index at the national level for Covid-19 related terms was 4 , 533 (IQR (Interquartile Range) =1, 301) before the outbreak (January 12017 to December 30 2019), and 314, $718($ IQR=445, 074) after the outbreak (December 312019 to March 15 2021). The median provincial level search index ranged from 63 (IQR=7) in Tibet to 1,138 (IQR=302) in Guangdong before Covid-19, and ranged from 1,186 (IQR=983) in Tibet to 38, 061(IQR=45, 785) in Guangdong. The crude relative change in the median of search index ranged from 2 099\% in Tibet and 2 034\% in Hainan to 3 872\% in Beijing and 4 294\% in Liaoning (Table 1). 89, 936 cases of SARS-COV-2 occurred nationwide (including 1 case in Tibet and 68, 021 in Hubei) from 31 December 2020 to March 15 2021. The number of confirmed cases outside Tibet and Hubei ranged from 18 (0.1\%) in Qinghai to 2, 245 (10.6\%) in Guangdong province. In conjunction with these search patterns, $13 \%, 76 \%$ and $11 \%$ of confirmed Covid-19 cases were reported in January 2020, February 2020 and from March 2020 to March 2021 respectively. 
Table 1

Comparison of search index in the COVID-19 and pre-COVID period

\begin{tabular}{|c|c|c|c|c|c|}
\hline & \multicolumn{2}{|c|}{$\begin{array}{l}\text { Pre-Covid-19 Period } \\
\text { (Jan } 1 \text { 2017- Dec } 30 \text { 2019) }\end{array}$} & \multicolumn{2}{|c|}{$\begin{array}{l}\text { Covid-19 Period } \\
\text { (Dec } 31 \text { 2019- Mar } 15 \text { 2021) }\end{array}$} & \multirow[t]{2}{*}{$\begin{array}{l}\text { Relative Change } \\
(\%)\end{array}$} \\
\hline & Median & IQR & Median & IQR & \\
\hline \multicolumn{6}{|l|}{ Low HDI } \\
\hline Tibet & 63 & 7 & 1386 & 983 & 2099 \\
\hline Yunnan & 290 & 79 & 7939 & 7612 & 2642 \\
\hline Guizhou & 224 & 87 & 7011 & 6531 & 3030 \\
\hline Gansu & 175 & 74 & 5304 & 6348 & 2931 \\
\hline Qinghai & 73 & 33 & 2465 & 1625 & 3277 \\
\hline Xinjiang & 176 & 56 & 6108 & 7744 & 3370 \\
\hline Guangxi & 303 & 119 & 7548 & 9863 & 2391 \\
\hline Sichuan & 536 & 167 & 15792 & 19522 & 2846 \\
\hline Anhui & 324 & 124 & 11199 & 13205 & 3356 \\
\hline Ningxia & 86 & 59 & 2569 & 2019 & 2887 \\
\hline \multicolumn{6}{|l|}{ Middle HDI } \\
\hline Jiangxi & 274 & 96 & 8021 & 8726 & 2827 \\
\hline Henan & 489 & 152 & 15319 & 17469 & 3033 \\
\hline Hebei & 435 & 152 & 18986 & 26505 & 4270 \\
\hline Hunan & 348 & 124 & 11216 & 13615 & 3123 \\
\hline Shanxi & 263 & 84 & 8674 & 11963 & 3198 \\
\hline Hainan & 157 & 53 & 3351 & 2709 & 2034 \\
\hline Chongqing & 272 & 97 & 7965 & 8692 & 2828 \\
\hline Heilongjiang & 279 & 88 & 10902 & 15782 & 3808 \\
\hline Shaanxi & 356 & 116 & 9111 & 11704 & 2463 \\
\hline Hubei & 404 & 137 & 10723 & 11385 & 2554 \\
\hline Fujian & 462 & 155 & 10842 & 11205 & 2247 \\
\hline Inner Mongolia & 207 & 72 & 6747 & 8116 & 3167 \\
\hline Jilin & 234 & 76 & 9375 & 12607 & 3906 \\
\hline \multicolumn{6}{|l|}{ High HDI } \\
\hline Shandong & 597 & 210 & 21802 & 31866 & 3555 \\
\hline Guangdong & 1138 & 302 & 38061 & 45784 & 3246 \\
\hline Liaoning & 365 & 144 & 16001 & 24060 & 4284 \\
\hline Zhejiang & 754 & 250 & 22516 & 26850 & 2886 \\
\hline Jiangsu & 789 & 253 & 23453 & 30053 & 2874 \\
\hline Tianjin & 247 & 84 & 7516 & 8409 & 2943 \\
\hline Shanghai & 622 & 194 & 16430 & 19065 & 2541 \\
\hline Beijing & 647 & 204 & 25699 & 36265 & 3872 \\
\hline
\end{tabular}


Model Estimated change of search index by HDI categories.

As shown in Table 2, there was a 10\% (relative risk (RR)=1.10, 95\% Cl: 1.07-1.13, $\mathrm{p}<.0001), 11 \%(\mathrm{RR}=1.11,95 \% \mathrm{Cl}$ : 1.08-1.14, $\mathrm{p}<.0001)$ and 13\% $(\mathrm{RR}=1.13,95 \% \mathrm{Cl}: 1.10-1.16, \mathrm{p}<.0001)$ annual increase in the research index before the pandemic among regions with low, middle and high HDI respectively. The difference in pre-Covid-19 trends of the search index among the three HDI groups was not statistically significant (middle vs. low, ratio of $R R=1.01, p=0.6188$; high vs. low, ratio of $R R=. .03, p=0.2239$ ) (Table 2, Figure 1). 
Table 2

Model estimated change of search index by HDI categories

\begin{tabular}{|c|c|c|c|c|c|c|c|c|c|c|c|}
\hline & \multicolumn{3}{|c|}{ Regions with Low HDI } & \multicolumn{4}{|c|}{ Regions with Middle HDI } & \multicolumn{4}{|c|}{ Regions with High HDI } \\
\hline & $\begin{array}{l}\text { RR } \\
(95 \% \\
\text { Cl) }\end{array}$ & $\begin{array}{l}\mathrm{p} \text { - } \\
\text { value }\end{array}$ & $\begin{array}{l}\text { Ratio of } \\
\text { RR }\end{array}$ & $\begin{array}{l}\text { RR } \\
(95 \% \\
\text { Cl) }\end{array}$ & $\begin{array}{l}\text { p- } \\
\text { value }\end{array}$ & $\begin{array}{l}\text { Ratio } \\
\text { of } \\
\mathrm{RR}^{*}\end{array}$ & $\begin{array}{l}\text { p- } \\
\text { value }\end{array}$ & $\begin{array}{l}\text { RR } \\
(95 \% \\
\mathrm{Cl})\end{array}$ & $\begin{array}{l}\mathrm{p}- \\
\text { value }\end{array}$ & $\begin{array}{l}\text { Ratio } \\
\text { of } \\
\mathrm{RR}^{\star}\end{array}$ & $\begin{array}{l}\mathrm{p}- \\
\text { value }\end{array}$ \\
\hline \multicolumn{12}{|l|}{$\begin{array}{l}\text { Pre- } \\
\text { pandemic }\end{array}$} \\
\hline $\begin{array}{l}\text { Yearly } \\
\text { change Jan } \\
12016 \text { - Dec } \\
302019\end{array}$ & $\begin{array}{l}1.10 \\
(1.07 \\
1.13)\end{array}$ & $<.0001$ & Reference & $\begin{array}{l}1.11 \\
(1.08 \\
1.14)\end{array}$ & $<.0001$ & $\begin{array}{l}1.01 \\
(0.97 \\
1.05)\end{array}$ & .6188 & $\begin{array}{l}1.13 \\
(1.10 \\
1.16)\end{array}$ & $<.0001$ & $\begin{array}{l}1.03 \\
(0.98 \\
1.07)\end{array}$ & .2239 \\
\hline \multicolumn{12}{|l|}{$\begin{array}{l}\text { Initial COVID- } \\
19 \text { Wave }\end{array}$} \\
\hline $\begin{array}{l}\text { Level } \\
\text { Change on } \\
\text { Dec } 312019\end{array}$ & $\begin{array}{l}1.41 \\
(1.34 \\
1.49)\end{array}$ & $<.0001$ & Reference & $\begin{array}{l}1.62 \\
(1.54 \\
1.70)\end{array}$ & $<.0001$ & $\begin{array}{l}1.15 \\
(1.07 \\
1.23)\end{array}$ & .0002 & $\begin{array}{l}1.58 \\
(1.48, \\
1.68)\end{array}$ & $<.0001$ & $\begin{array}{l}1.12 \\
(1.03, \\
1.21)\end{array}$ & .0091 \\
\hline $\begin{array}{l}\text { Level change } \\
\text { Jan } 18 \\
\text { (HHT } \\
\text { announced) } \\
\text { - Jan } 25 \\
2020 \\
\text { (lockdown) }\end{array}$ & $\begin{array}{l}106.80 \\
(100.07, \\
113.99)\end{array}$ & $<.0001$ & Reference & $\begin{array}{l}124.55 \\
(117.61, \\
131.90)\end{array}$ & $<.0001$ & $\begin{array}{l}1.16 \\
(1.07, \\
1.27)\end{array}$ & .0004 & $\begin{array}{l}125.31 \\
(116.53 \\
134.75)\end{array}$ & $<.0001$ & $\begin{array}{l}1.17 \\
(1.06 \\
1.30)\end{array}$ & .0012 \\
\hline $\begin{array}{l}\text { Weekly } \\
\text { change Jan } \\
25-\text { Jun } 10 \\
2020\end{array}$ & $\begin{array}{l}0.90 \\
(0.89 \\
0.90)\end{array}$ & $<.0001$ & Reference & $\begin{array}{l}0.89 \\
(0.88 \\
0.89)\end{array}$ & $<.0001$ & $\begin{array}{l}0.99 \\
\\
(0.98 \\
0.99)\end{array}$ & $<.0001$ & $\begin{array}{l}0.89 \\
(0.89 \\
0.90)\end{array}$ & $<.0001$ & $\begin{array}{l}0.99 \\
\\
(0.99 \\
1.00)\end{array}$ & .0768 \\
\hline $\begin{array}{l}\text { Beijing } \\
\text { Outbreak }\end{array}$ & & & & & & & & & & & \\
\hline $\begin{array}{l}\text { Level change } \\
\text { Jun } 11 \text {-Jun } \\
172020\end{array}$ & $\begin{array}{l}1.91 \\
(1.79 \\
2.03)\end{array}$ & $<.0001$ & Reference & $\begin{array}{l}1.34 \\
(1.26 \\
1.42)\end{array}$ & $<.0001$ & $\begin{array}{l}1.01 \\
(0.94 \\
1.10)\end{array}$ & .7419 & $\begin{array}{l}2.12 \\
(1.98 \\
2.27)\end{array}$ & $<.0001$ & $\begin{array}{l}1.11 \\
(1.01 \\
1.21)\end{array}$ & .0227 \\
\hline $\begin{array}{l}\text { Weekly } \\
\text { change Jun } \\
17 \text { - Oct } 11 \\
2020\end{array}$ & $\begin{array}{l}0.96 \\
(0.95 \\
0.96)\end{array}$ & $<.0001$ & Reference & $\begin{array}{l}1.02 \\
(1.01 \\
1.02)\end{array}$ & $<.0001$ & $\begin{array}{l}0.99 \\
(0.98 \\
1.00)\end{array}$ & .0059 & $\begin{array}{l}0.94 \\
(0.93 \\
0.94)\end{array}$ & $<.0001$ & $\begin{array}{l}0.98 \\
\\
(0.97 \\
0.99)\end{array}$ & $<.0001$ \\
\hline $\begin{array}{l}\text { Qingdao } \\
\text { Outbreak }\end{array}$ & & & & & & & & & & & \\
\hline $\begin{array}{l}\text { Level } \\
\text { Change on } \\
\text { Oct } 12 \text { th }\end{array}$ & $\begin{array}{l}1.31 \\
(1.23 \\
1.40)\end{array}$ & $<.0001$ & Reference & $\begin{array}{l}1.34 \\
(1.26 \\
1.42)\end{array}$ & $<.0001$ & $\begin{array}{l}1.02 \\
(0.93 \\
1.11)\end{array}$ & .6979 & $\begin{array}{l}1.41 \\
(1.31 \\
1.52)\end{array}$ & $<.0001$ & $\begin{array}{l}1.07 \\
(0.97 \\
1.18)\end{array}$ & .1693 \\
\hline $\begin{array}{l}\text { Weekly } \\
\text { change in } \\
\text { winter wave } \\
\text { Oct } 122020 \\
\text { - Jan } 32021\end{array}$ & $\begin{array}{l}1.01 \\
(1.00 \\
1.01)\end{array}$ & 0.0647 & Reference & $\begin{array}{l}1.02 \\
(1.01 \\
1.02)\end{array}$ & $<.0001$ & $\begin{array}{l}(0.99 \\
1.02)\end{array}$ & .1043 & $\begin{array}{l}1.02 \\
(1.01 \\
1.03)\end{array}$ & .0002 & $\begin{array}{l}(0.99 \\
1.02)\end{array}$ & .1058 \\
\hline $\begin{array}{l}\text { Shijiazhuang } \\
\text { Outbreak }\end{array}$ & & & & & & & & & & & \\
\hline $\begin{array}{l}\text { Level change } \\
\text { Jan 3- Jan } 7 \\
2021\end{array}$ & $\begin{array}{l}2.00 \\
(1.85 \\
2.16)\end{array}$ & $<.0001$ & Reference & $\begin{array}{l}2.67 \\
(2.50 \\
2.86)\end{array}$ & $<.0001$ & $\begin{array}{l}1.34 \\
(1.21, \\
1.48)\end{array}$ & $<.0001$ & $\begin{array}{l}2 . .45 \\
(2.24 \\
2.67)\end{array}$ & $<.0001$ & $\begin{array}{l}1.22 \\
(1.09 \\
1.37)\end{array}$ & .0007 \\
\hline
\end{tabular}

* In reference to the low HDI category 


\begin{tabular}{|c|c|c|c|c|c|c|c|c|c|c|c|}
\hline \multirow{3}{*}{$\begin{array}{l}\text { Weekly } \\
\text { change Jan } \\
7-\text { Mar } 15 \\
2021\end{array}$} & \multicolumn{3}{|c|}{ Regions with Low HDI } & \multicolumn{4}{|c|}{ Regions with Middle HDI } & \multicolumn{4}{|c|}{ Regions with High HDI } \\
\hline & 0.83 & $<.0001$ & Reference & 0.80 & $<.0001$ & 0.95 & $<.0001$ & 0.78 & $<.0001$ & 0.94 & $<.0001$ \\
\hline & $\begin{array}{l}(0.82, \\
0.84)\end{array}$ & & & $\begin{array}{l}(0.79 \\
0.80)\end{array}$ & & $\begin{array}{l}(0.94, \\
0.97)\end{array}$ & & $\begin{array}{l}(0.77 \\
0.79)^{\prime}\end{array}$ & & $\begin{array}{l}(0.93, \\
0.96)\end{array}$ & \\
\hline
\end{tabular}

During the initial wave, the search index increased by $41 \%, 62 \%$ and 58\% on December 31, 2019 among regions with low (RR=1.41, $95 \%$ Cl: 1.34-1.49, $\mathrm{p}<.0001)$, middle (RR=1.62, 95\% Cl: 1.54-1.70, $\mathrm{p}<.0001)$ and high (RR=1.58, 95\% Cl: 1.48-1.68, $\mathrm{p}<0.0001) \mathrm{HDI}$, respectively. The immediate increase in middle and high HDI regions was statistically significantly higher than the increase in low HDI regions (middle vs. low, ratio of $\mathrm{RR}=1.15, \mathrm{p}=.0002$; high vs. low, ratio of $\mathrm{RR}=1.12, \mathrm{p}=.0091$ ). Similarly, there was a 107-fold, 125-fold and 125-fold increase in search index between January 18 and January 25 2020, the period shortly after the official announcement of human-to-human transmission (HHT), among regions with low ( $R R=106.8,95 \% \mathrm{Cl}: 100.1-114.0, p<.0001)$, middle ( $R R=124.6,95 \% \mathrm{Cl}: 117.6-131.9, p<.0001)$ and high ( $R R=125.3,95 \%$ Cl: 116.5-134.8, p<.0001) HDI, respectively. The immediate increase in this short period among middle and high HDI regions were statistically significantly higher than the increase in low HDI regions (middle vs. low, ratio of RR=1.16, $p=.0004$; high vs. low, ratio of RR=1.17, $p=.0012$ ). From the peak of the search index on January 25 to June 10 2020, a 10\%, 11\% and 11\% decrease per week was observed in the search index among regions with low ( $R R=0.90,95 \% \mathrm{Cl}$ : 0.89-0.90, $p<.0001)$, middle ( $R R=0.89,95 \% \mathrm{Cl}: 0.88-0.89, p<.0001)$ and high (RR=0.89, 95\% Cl: 0.89$0.90, \mathrm{p}<.0001) \mathrm{HDI}$, respectively (Table 2).

The outbreak in Beijing was associated with a 91\%, 34\% and 112\% increase in the search index among regions with low (RR=1.91, 95\% Cl: 1.79-2.03, $p<.0001)$, middle ( $R R=1.34,95 \%$ Cl: 0.94-1.10, $p<.0001)$ and high (RR=2.12, 95\% Cl: 1.98-2.27, p<.0001) HDI, respectively, in the first week (June 11-17 2020) of the outbreak. Additionally, the Beijing outbreak was associated with an increase in the monthly change rate of the search index. From June 17 to October 11 2020, a 4\% decrease, 2\% increase and 6\% decrease per month in the search index was observed among regions with low ( $R R=0.96,95 \% \mathrm{Cl}$ : 0.95-0.96, $p<0.0001)$, middle ( $R R=1.02,95 \% \mathrm{Cl}: 1.01-1.02, p<.0001)$ and high ( $R R=0.94,95 \% \mathrm{Cl}$ : 0.93-0.94, p<.0001) HDI, respectively (Table 2).

The Qingdao outbreak was associated with a comparable 31\%, 34\% and 41\% immediate increase in the search index among regions with low ( $R R=1.31,95 \%$ Cl: 1.23-1.40, p<.0001), middle (RR=1.34, 95\% Cl: 1.26-1.42, p<.0001) and high (RR=1.41, 95\% Cl: 1.31-1.52, p<.0001) HDI, respectively. In the winter wave after the Qingdao outbreak, search index increased by $1 \%, 2 \%$ and $2 \%$ per week among regions with low $(R R=1.01,95 \%$ Cl: 1.00-1.01, $p=.0647)$, middle (RR=1.02, 95\% Cl: 1.01-1.02, $p<0.0001)$ and high (RR=1.02, 95\% Cl: 1.01-1.03, $p=.0002)$ HDI, respectively.

The Shijiazhuang outbreak in January 2021 was associated with a 167\% and 145\% immediate increase in search index among ) regions with middle ( $R R=2.67,95 \% \mathrm{Cl}: 2.50-2.86, \mathrm{p}<0.0001)$ and high ( $\mathrm{RR}=2.45,95 \% \mathrm{Cl}$ : 2.24-2.67, $\mathrm{p}<.0001)$ HDI, respectively, higher than the 100\% increase $(R R=2.00,95 \% \mathrm{Cl}: 1.85-2.16, p<.0001)$ in regions with low HDI (middle vs. low, ratio of $R R=1.34, p<.0001$; high vs. low, the ratio of $R R=1.22$, $\mathrm{p}=.0007$ ). However, the $20 \%$ and $22 \%$ weekly decrease in search index after the Shijiazhuang outbreak among regions with middle (RR=0.80, $95 \% \mathrm{Cl}: 0.79-0.80, \mathrm{p}<.0001)$ and high (RR=0.78, 95\% Cl: 0.77-0.79, $\mathrm{p}<.0001) \mathrm{HDI}$, respectively, was statistically significantly greater ( $<<.0001)$ than the $17 \%$ monthly decrease in the region with low $\mathrm{HDI}(\mathrm{RR}=0.83,95 \% \mathrm{Cl}: 0.82-0.84, \mathrm{p}<.0001)$. Figure 2 illustrated the heterogeneity in the immediate relative change in the search index following each pre-specified exposure across the country.

Association between HDI, CNPPP, education, life expectancy and magnitude of change in the search index.

The results from models where HDI or its component was coded as a continuous variable were consistent with findings from our main analysis. As shown in Table S1, the pre-pandemic trends in two provinces differing in HDI, GNPPP education year or life expectancy by one standard deviation were similar ( $p>0.1)$. The immediate relative increase in the search index in a province with one standard higher HDI was statistically higher (initial wave: Ratio of $R R=1.09, p<.0001$; HHT announcement: Ratio of $R R=1.04 p=.0395$; Beijing outbreak: Ratio of $R R=1.06, p=.0090$; Qingdao outbreak: Ratio of $R R=1.04, p=0.0324$; Shijiazhuang outbreak: Ratio of $R R=1.11, p<0.0001$ ). In contrast, the gradual decrease in the search index in a province with one standard higher HDI after each exposure was either similar or greater. For each exposure, the difference associated with GNPPP, education year or life expectancy in the directions and magnitudes of both immediate and gradual effect across provinces was similar to the difference associated with HDI.

\section{Discussion}

The study used the Baidu search index related to COVID-19 at the subnational level to analyze the search volume of Chinese Internet users for COVID-19, which was used to reflect the level of public awareness of COVID-19, and the differences in levels of awareness of and proactive information-seeking response to COVID-19 in different regions. Our study found that, in January 2020, the outbreak of the Wuhan epidemic 
triggered an increase in search terms for COVID-19 among Internet users in different regions. In particular, this increasing trend was most sharply observed between 18 January and 25 January 2020, a period when Chinese television, radio and newspapers reported the confirmation of human-to-human transmission of SARS-CoV-2, greatly increasing public awareness of the threat of the disease. This was reflected in a huge increase in search indices. In the later outbreaks, we also found that each subsequent outbreak in China also renewed public interest in COVID-19, which resulted in the increasing search volume for COVID-19-related keywords. However, the subsequent increase in COVID-19 searches did not surpass the first search index apex, which may be explained by individuals having accumulated prior knowledge already and becoming more accustomed to subsequent COVID-19 outbreaks, as well as by the fact that subsequent outbreaks were less severe.

When the Wuhan municipal government issued a notification about the existence of unknown respiratory syndrome at the end of December 2021, the public response was reminiscent of the fear caused by SARS in 2003, especially as little was known about this new pneumonia. On January 20, the confirmation of human-to-human transmission of COVID-19 was announced through television, radio, and newspaper. After being informed of their susceptibility to COVID-19, the public across China rushed to seek related information online ${ }^{23,24}$. These increases happened in just 3 days, from 20 Jan to 23 Jan. In contrast, global collective public attention to COVID-19 reached its peak on 12 March, following the declaration of Public Health Emergency of International Concern (PHEIC) by the World Health Organization ${ }^{25,26}$. The surge of public collective attention to COVID-19 in China during the early stage of the outbreak could be attributed to governments at all levels mobilizing the whole society to contain the COVID-19 in China ${ }^{27}$. In addition, the first spike in search volume for COVID-19 related keywords occurred that same day across all provinces in China, which was different from the subnational patterns in the US where state-level search volume typically peaked at the time the first COVID-19 case was announced in the state $2,28,29$.

We further found that, after the first information-seeking peak, although there was an evident decline in the search interests in COVID-19 related words from February to April 2021, the public concern (reflected by the search interests) about the COVID-19 pandemic remained at a high level in every province and through the end of our study period. As Chinese government took the nationwide, stringent nonpharmaceutical interventions, China saw success in its initial containment of COVID-19, as the daily new local cases were under 10 from late March to late April ${ }^{30}$.In the context of the zero-tolerance policy in China, and few new cases of COVID-19, news of any new domestically occurring cases of COVID-19 in China generated a relatively large amount of media attention. For example, in Beijing in June 2020, a sporadic outbreak of 335 new COVID-19 cases (and no deaths) occurred due to imported frozen products ${ }^{31}$. Despite the limited nature of this local outbreak, it nonetheless generated intense public interest in Beijing and throughout the country. Such increased attention to new COVID-19 outbreaks in China suggests widespread, enduring awareness among the public about the ongoing risks of COVID-19.

We found social inequalities in information-seeking behavior intensity within China. Studies have confirmed that deprived populations show relatively lower awareness of infectious diseases, including H1N1 and COVID-19 ${ }^{32,33}$. In our findings, these inequalities are evidenced by the absolute change in Baidu Index volume as well as the speed with which peak search volume is achieved. Populations in areas with higher human development showed a higher volume of COVID-19 related searches, and their searches increased faster and maintained a relatively lower decline rate, which suggests not only the population living in HDIs areas have a faster response to COVID-19 but also maintained a heightened, more durable awareness about the COVID-19 epidemic. Lower awareness of COVID-19 may result in less attention paid to personal mitigation techniques and lower compliance with non-pharmaceutical interventions, which together may puts deprived populations at greater risk of contracting COVID-19. Due to the lower incidence and mortality of COVID-19 in China, it is difficult to analyze how social inequalities may have impact COVID-19 infections and related health outcomes in China. However, our analysis provides some evidence to support that there exist evident social inequalities in information-seeking reactions to and awareness of COVID-19 in China, potentially exacerbating existing inequalities in COVID-19 related physical and mental health comes for both short and long term ${ }^{12,34}$.

Our study is subject to several limitations. First, our study only attempts to use the analysis of internet users' information-seeking behavior to reflect public concern about COVID-19. Although Baidu search is the most commonly used search engine in China with the highest market share, our findings could not be generalized to people that do not have access to the Internet. In addition, as a disproportionately higher fraction of individuals without access to the internet have low SES and lower level of knowledge about the disease (reference), we may have underestimated the inequalities in the information-seeking response among regions with different SES's. Furthermore, we were not able to explore how individuals reacted to a health crisis using more disaggregated, individual-level data, such as data from surveys. We were able to examine how patterns of information-seeking responses differed according to the area-level HDI metric and used this measure to generate a hypothesis about potential associations with respect to individual factors, including education and income.

We used Baidu search data to analyze the first wave of the COVID-19 epidemic in China and several subsequent small outbreaks and found that there was an unprecedented increase in public awareness of the COVID-19 epidemic in China, and that the several subsequent outbreaks also sparked intense concern among internet users across China. Changes in the patterns of search interest in COVID-19 in each province of China were nearly synchronous during the first wave of the COVID-19 pandemic and subsequent local outbreaks, irrespective of the location of 
the epicenter of each outbreak and the variation in pandemic severity across the country. However, social inequalities in public response and awareness of COVID-19 were apparent, with less search interest observed in less developed areas compared with developed areas.

\section{Methods}

\subsection{Data Sources}

Baidu is the most popular search engine in China. The Baidu index (BI) is measured as the weighted frequency of unique searches for a search keyword or phrase relative to total search volume on Baidu on a given day ${ }^{35}$. We used the Baidu index of COVID-19 related search

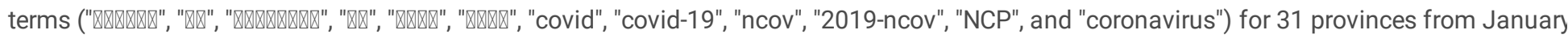
12017 to March 152021 in China to reflect public interest in COVID-19 during the pandemic in China. The provincial daily confirmed COVID19 cases were retrieved from official daily report ${ }^{36}$. The provincial-level human development index (HDI), an area-level measure of socioeconomic status, was retrieved from the China National Human Development Report 2019 to reflect regional-level SES ${ }^{10,37}$. A key advantage to examining an area-level measure in this context is its utility in providing evidence to help guide community-level interventions and policies. Other area-level measures by province, including the Gross National Product per person (GNPPP), the average number of years of education received by people ages 25 and older, and mean life expectancy at birth, which were used to calculate the HDI index, were extracted from the statistical yearbook and publicly available reports. ${ }^{38}$ This study was exempt from institutional review oversight as the data are publicly available and aggregated at the population level.

Our aim was to examine a series of three interrelated research questions, including (1) Did the Covid-19 outbreak lead to statistically significant increase in the Baidu Index of Covid-19 related terms? (2) What was the magnitude of the increases in searches compared to preCovid-19 forecasted trends, and how did these increases differ by regions with different social-economic development levels, and (3) Did the collective attention diminish toward pre-Covid-19 levels after the pandemic apex, and how did this differ according to the human development index (HDI)?

\subsection{Statistical analysis}

After the initial exploration of search indices over time, we adopted an interrupted time series design to examine the effects of Covid-19. The effect was modeled using a segmented log-normal regression parameterization ${ }^{39-42}$ defining both pre-Covid trends (January 12017 December 30 2019), and distinct post-Covid periods that reflected different pandemic periods as experienced within China. Due to known large provincial-level heterogeneity in baseline levels as well as long-term trends, we employed mixed-effects models with random intercepts and random slopes over time, with individual provinces representing the random effects ${ }^{40}$. To adjust for observed seasonal and weekly cyclical patterns, we included fixed-effects of monthly and weekly indicator variables in all models. The Poisson model equation estimating the daily search index was expressed as follows:

$$
\begin{aligned}
& E\left(\ln \left(\text { Index }_{i t}\right)\right)=\beta_{0 i}+\beta_{1 i} T+\beta_{c} \text { Covid }^{2} H D I_{i}+\beta_{c 1}{\text { Covid } 1 * H D I_{i}}+\beta_{c s 1} T_{1} * H D I_{i}+\beta_{c 2}{\text { Covid } 2 * H D I_{i}}+\beta_{c s 2} \text { Covid } 2_{2} * H D I_{i}
\end{aligned}
$$

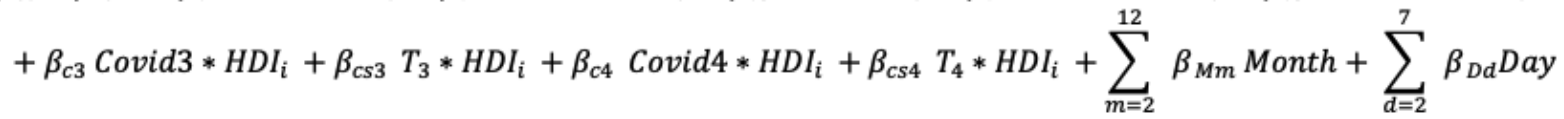

In the model, Index ${ }_{i t}$ denotes the value of the search index in province $i$ at time $t$. $\mathrm{HDI}_{\mathrm{i}}$ is the HDI category (low, middle or high) for province $i$. $\beta_{0 i}$ represents the model intercept with both a fixed effect and province-level random effects, $\beta_{1 i}$ represents the underlying pre-Covid-19 secular trends with both a fixed effect and province-level random effects. The five distinct indicator variables (Covid, Covid1, Covid2, Covid3 and Covid4) are used to define the exposures or intervals: 1) December 31 2019, the estimated start of the first Covid-19 wave; 2) 18 January 2020 (official announcement of human-to-human transmission) to Jan 25 January 2020 (shortly after the lockdown and the estimated peak of daily search index in the initial Covid-19 wave);3) a second outbreak in Beijing starting on June 11;4) the outbreak in Qingdao starting on October $122020 ; 5)$ the outbreak in Shijiazhuang starting on January 32021 . $T$ is the time (days) elapsed since the start of the study, and $T_{1}$, $T_{2}, T_{3}$, and $T_{4}$ represent the days since the estimated peak (25 January 2020, June 17 2020, October 122020 and January 7 2021) of the daily search index associated with each distinct exposure, respectively. We interacted the main effect terms with strata of HDI categories, examining the extent to which the change in search index associated with each exposure differed by area-level socioeconomic status. Month and Day are individual dummy variables indexing month of the year using the month of January as the reference category, and the day of the week using Friday as the reference category respectively. An AR (1) correlation structure was used to accommodate autocorrelation in residual errors. In order to estimate the association of each component of HDI with the change of search index, we replaced $\mathrm{HDI}_{\mathrm{i}}$ in the equation by standardized HDI (continuous variable), GNPPP, years of education or life expectancy and repeated all the analyses. 
We employed a linear mixed-model with logarithmic transformation of the independent variable and a normal residual distribution ${ }^{43}$. We used a mixed-effects log-normal model rather than a negative bionomial or Poisson model for three reasons. First, an attempt to run these generalized linear models with log link (e.g Poisson and negative binomial model) failed to converge without simplifications such as the elimination of an $\operatorname{AR}(1)$ correlation structure in residual errors and the elimination of provincial-level random slopes. Second, mixed effect lognormal models provided a better fit to the data patterns than the fixed-effect log-normal models and generalized linear models judged by Akaike's Information Criteria (AIC) and Bayesian Information Criteria (BIC). Third, there was no evidence of issues with heteroscedasticity in the residuals departure from a normal distribution in the error distribution when using the log normal model.

All analyses were conducted in R-version-4.0.2 using data obtained March 31, 2021. A two-sided alpha value of 0.05 indicated statistical significance. This study is reported as per the Strengthening the Reporting of Observational Studies in Epidemiology (STROBE) guidelines for cohort studies.

\subsection{Data availability}

The data that support the findings of this study are available from the corresponding author upon request.

\section{Declarations}

Author Contribution: Zhicheng Wang and Hong Xiao had full access to, verified all the data in the study, and take responsibility for the integrity of the data and the accuracy of data analysis.

Conceptualization and data curation: Zhicheng Wang and Hong Xiao

Supervision: Joseph M Unger and Kun Tang

Methodology: Hong Xiao and Zhicheng Wang

Statistical analysis and programing: Hong Xiao

Software: Hong Xiao

Visualization: Hong Xiao and Zhicheng Wang

Writing-first draft: Zhicheng Wang and Hong Xiao

Writing-review \& editing: all authors

Administrative, technical, or material support: Kun Tang

Obtained funding: Kun Tang

\section{Declaration of Competing Interest}

The authors declare no competing interests related to the study

\section{Funding}

National Natural Science Foundation of China (72074130)

Spring Breeze Foundation of Tsinghua University (20203080035).

\section{Acknowledgement}

We thank Dr. Zhongyue Yan for his technical support to the generation of the geographic maps.

\section{References}

1. The State Council Information Office of the People's Republic of China. Fighting COVID-19: China in Action, < http://english.scio.gov.cn/whitepapers/2020-06/07/content_76135269.htm, accessed by 20 June 2021> (2020).

2. Bento, A. I. et al. Evidence from internet search data shows information-seeking responses to news of local COVID-19 cases. Proc Natl Acad Sci U S A 117, 11220-11222, doi:10.1073/pnas.2005335117 (2020). 
3. Mangono, T. et al. Information-Seeking Patterns During the COVID-19 Pandemic Across the United States: Longitudinal Analysis of Google Trends Data. J Med Internet Res 23, e22933, doi:10.2196/22933 (2021).

4. Venkatesh, U. \& Gandhi, P. A. Prediction of COVID-19 Outbreaks Using Google Trends in India: A Retrospective Analysis. Healthc Inform Res 26, 175-184, doi:10.4258/hir.2020.26.3.175 (2020).

5. Corpuz, J. C. G. Adapting to the culture of 'new normal': an emerging response to COVID-19. J Public Health (Oxf) 43, e344-e345, doi:10.1093/pubmed/fdab057 (2021).

6. Daly, M. \& Robinson, E. Psychological distress and adaptation to the COVID-19 crisis in the United States. J Psychiatr Res 136, 603-609, doi:10.1016/j.jpsychires.2020.10.035 (2021).

7. Jones, J. et al. Similarities and Differences in COVID-19 Awareness, Concern, and Symptoms by Race and Ethnicity in the United States: Cross-Sectional Survey. J Med Internet Res 22, e20001, doi:10.2196/20001 (2020).

8. Lin, L., Jung, M., McCloud, R. F. \& Viswanath, K. Media use and communication inequalities in a public health emergency: a case study of 2009-2010 pandemic influenza A virus subtype H1N1. Public Health Rep 129 Suppl 4, 49-60, doi:10.1177/00333549141296s408 (2014).

9. McCaffery, K. J. et al. Health literacy and disparities in COVID-19-related knowledge, attitudes, beliefs and behaviours in Australia. Public Health Res Pract 30, doi:10.17061/phrp30342012 (2020).

10. Subnational HDI, < https://globaldatalab.org/shdi/shdi/CHN/? levels=1\%2B4\&interpolation=0\&extrapolation=0\&nearest_real=0\&years=2019\%2B2018, accessed by 20 December 2020> (2020).

11. Wang, Z. \& Tang, K. Combating COVID-19: health equity matters. Nat Med 26, 458, doi:10.1038/s41591-020-0823-6 (2020).

12. Ahmed, F., Ahmed, N., Pissarides, C. \& Stiglitz, J. Why inequality could spread COVID-19. Lancet Public Health 5, e240, doi:10.1016/s24682667(20)30085-2 (2020).

13. Jacobs, W., Amuta, A. O. \& Jeon, K. C. Health information seeking in the digital age: An analysis of health information seeking behavior among US adults. Cogent Social Sciences 3, 1302785, doi:10.1080/23311886.2017.1302785 (2017).

14. Hassan, S. \& Masoud, O. Online health information seeking and health literacy among non-medical college students: gender differences. Journal of Public Health, doi:10.1007/s10389-020-01243-w (2020).

15. Kim, J. \& Jung, M. Associations between media use and health information-seeking behavior on vaccinations in South Korea. BMC Public Health 17, 700, doi:10.1186/s12889-017-4721-x (2017).

16. Tang, C., Wu, X., Chen, X., Pan, B. \& Yang, X. Examining income-related inequality in health literacy and health-information seeking among urban population in China. BMC Public Health 19, 221, doi:10.1186/s12889-019-6538-2 (2019).

17. Dewalt, D. A., Berkman, N. D., Sheridan, S., Lohr, K. N. \& Pignone, M. P. Literacy and health outcomes: a systematic review of the literature. J Gen Intern Med 19, 1228-1239, doi:10.1111/j.1525-1497.2004.40153.x (2004).

18. Beaunoyer, E., Dupéré, S. \& Guitton, M. J. COVID-19 and digital inequalities: Reciprocal impacts and mitigation strategies. Computers in Human Behavior 111, 106424, doi:https://doi.org/10.1016/j.chb.2020.106424 (2020).

19. Neter, E. \& Brainin, E. Vol. 24 68-81 (Hogrefe Publishing, Germany, 2019).

20. China's netizen population hits over 1 billion, < https://news.cgtn.com/news/2021-08-27/China-s-netizen-population-hits-over-1-billion1330NCedM5i/index.html, accessed by 16 September 2021> (2021).

21. Hu, D. et al. More effective strategies are required to strengthen public awareness of COVID-19: Evidence from Google Trends. J Glob Health 10, 011003, doi:10.7189/jogh.10.011003 (2020).

22. Mancuso, C. A. \& Rincon, M. Impact of health literacy on longitudinal asthma outcomes. J Gen Intern Med 21, 813-817, doi:10.1111/j.1525-1497.2006.00528.x (2006).

23. Gong, X., Han, Y., Hou, M. \& Guo, R. Online Public Attention During the Early Days of the COVID-19 Pandemic: Infoveillance Study Based on Baidu Index. JMIR Public Health Surveill 6, e23098, doi:10.2196/23098 (2020).

24. Li, C. et al. Retrospective analysis of the possibility of predicting the COVID-19 outbreak from Internet searches and social media data, China, 2020. Euro Surveill 25, doi:10.2807/1560-7917.Es.2020.25.10.2000199 (2020).

25. Jun, S.-P., Yoo, H. S. \& Lee, J.-S. The impact of the pandemic declaration on public awareness and behavior: Focusing on COVID-19 google searches. Technological Forecasting and Social Change 166, 120592, doi:https://doi.org/10.1016/j.techfore.2021.120592 (2021).

26. Effenberger, M. et al. Association of the COVID-19 pandemic with Internet Search Volumes: A Google Trends(TM) Analysis. Int $J$ Infect Dis 95, 192-197, doi:10.1016/j.ijid.2020.04.033 (2020).

27. Lai, S. et al. Effect of non-pharmaceutical interventions to contain COVID-19 in China. Nature 585, 410-413, doi:10.1038/s41586-0202293-x (2020).

28. Kurian, S. J. et al. Correlations Between COVID-19 Cases and Google Trends Data in the United States: A State-by-State Analysis. Mayo Clin Proc 95, 2370-2381, doi:10.1016/j.mayocp.2020.08.022 (2020).

Page 10/13 
29. Husain, I. et al. Fluctuation of Public Interest in COVID-19 in the United States: Retrospective Analysis of Google Trends Search Data. JMIR Public Health Surveill 6, e19969, doi:10.2196/19969 (2020).

30. Lai, S. et al. Effect of non-pharmaceutical interventions for containing the COVID-19 outbreak in China. medRxiv, doi:10.1101/2020.03.03.20029843 (2020).

31. Zhang, Y. et al. [Epidemiological characteristics of COVID-19 cases in outbreak in Xinfadi market in Beijing]. Zhonghua Liu Xing Bing Xue Za Zhi 42, 1-5, doi:10.3760/cma.j.cn112338-20201222-01428 (2021).

32. Lin, L., Savoia, E., Agboola, F. \& Viswanath, K. What have we learned about communication inequalities during the H1N1 pandemic: a systematic review of the literature. BMC Public Health 14, 484, doi:10.1186/1471-2458-14-484 (2014).

33. Ye, Y. et al. Preventive behaviours and family inequalities during the COVID-19 pandemic: a cross-sectional study in China. Infect Dis Poverty 10, 100, doi:10.1186/s40249-021-00884-7 (2021).

34. Wolf, M. S. et al. Awareness, Attitudes, and Actions Related to COVID-19 Among Adults With Chronic Conditions at the Onset of the U.S. Outbreak: A Cross-sectional Survey. Ann Intern Med 173, 100-109, doi:10.7326/m20-1239 (2020).

35. Huang, J., Zheng, R. \& Emery, S. Assessing the impact of the national smoking ban in indoor public places in china: evidence from quit smoking related online searches. PLoS One 8, e65577, doi:10.1371/journal.pone.0065577 (2013).

36. Daily briefing on novel coronavirus cases in China, < http://en.nhc.gov.cn/2021-09/23/c_84664.htm, accessed by 15 April 2021> (2021).

37. Smits, J. \& Permanyer, I. The Subnational Human Development Database. Scientific Data 6, 190038, doi:10.1038/sdata.2019.38 (2019).

38. China Statistical Yearbook 2020, < http://www.stats.gov.cn/tjsj/ndsj/2020/indexch.htm, accessed by 12 March 2021> (2020).

39. Xiao, H., Augusto, O. \& Wagenaar, B. H. Reflection on modern methods: a common error in the segmented regression parameterization of interrupted time-series analyses. Int J Epidemiol, doi:10.1093/ije/dyaa148 (2020).

40. Xiao, H. et al. The impact of the COVID-19 pandemic on health services utilization in China: Time-series analyses for 2016-2020. Lancet Reg Health West Pac 9, 100122, doi:10.1016/j.lanwpc.2021.100122 (2021).

41. Xiao, H. et al. Impact of Qingdao's smoke-free legislation on hospitalizations and mortality from acute myocardial infarction and stroke: an interrupted time-series analysis. Addiction 115, 1561-1570, doi:10.1111/add.14970 (2020).

42. Xiao, H. et al. Impact of smoke-free legislation on acute myocardial infarction and stroke mortality: Tianjin, China, 2007-2015. Tob Control 29, 61-67, doi:10.1136/tobaccocontrol-2018-054477 (2020).

43. Wagenaar, B. H. et al. The 2014-2015 Ebola virus disease outbreak and primary healthcare delivery in Liberia: Time-series analyses for 2010-2016. PLOS Medicine 15, e1002508, doi:10.1371/journal.pmed.1002508 (2018).

\section{Figures}




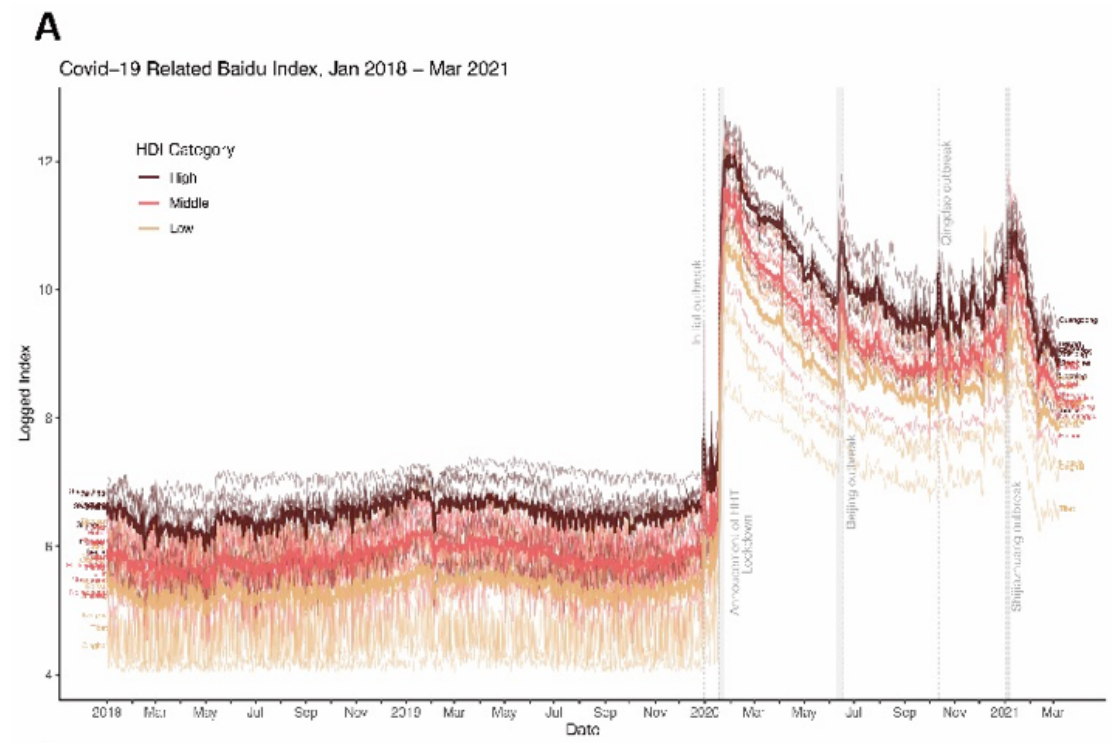

\section{B}

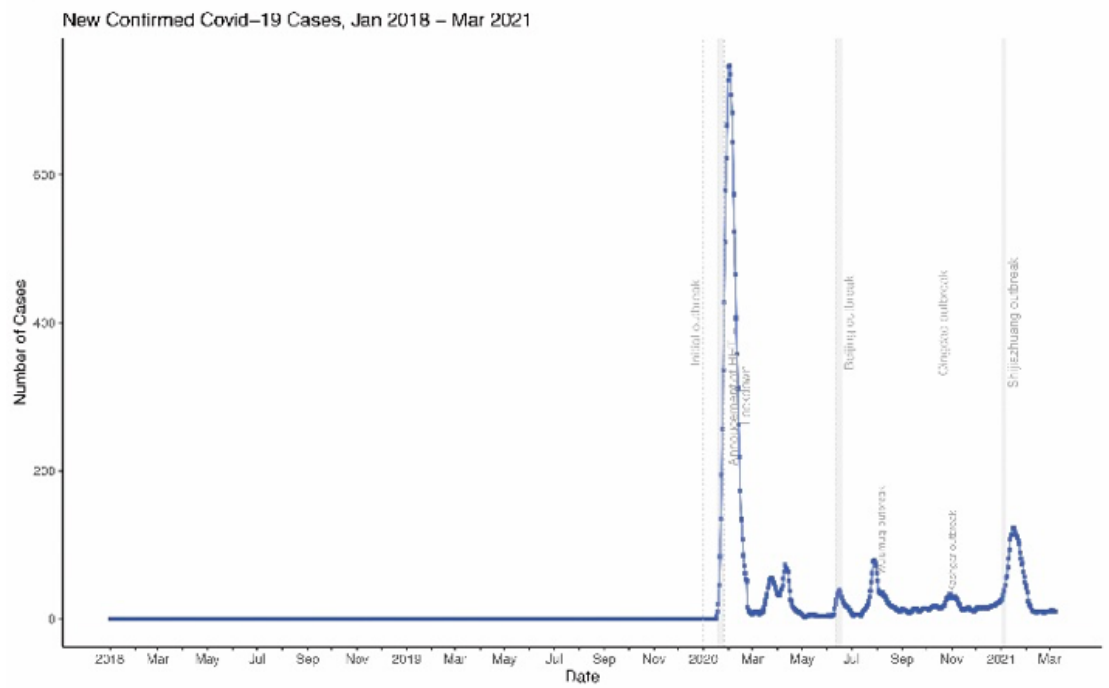

\section{Figure 1}

Baidu search index by province and number of new confirmed cases over time. (A) Observed daily search index (log transformed) by province and HDI category over time. Aggregated search index by HDI category over time is shown in Figure S1. (B) Daily new confirmed COVID-19 in China (cases in Hubei provinces are excluded). 

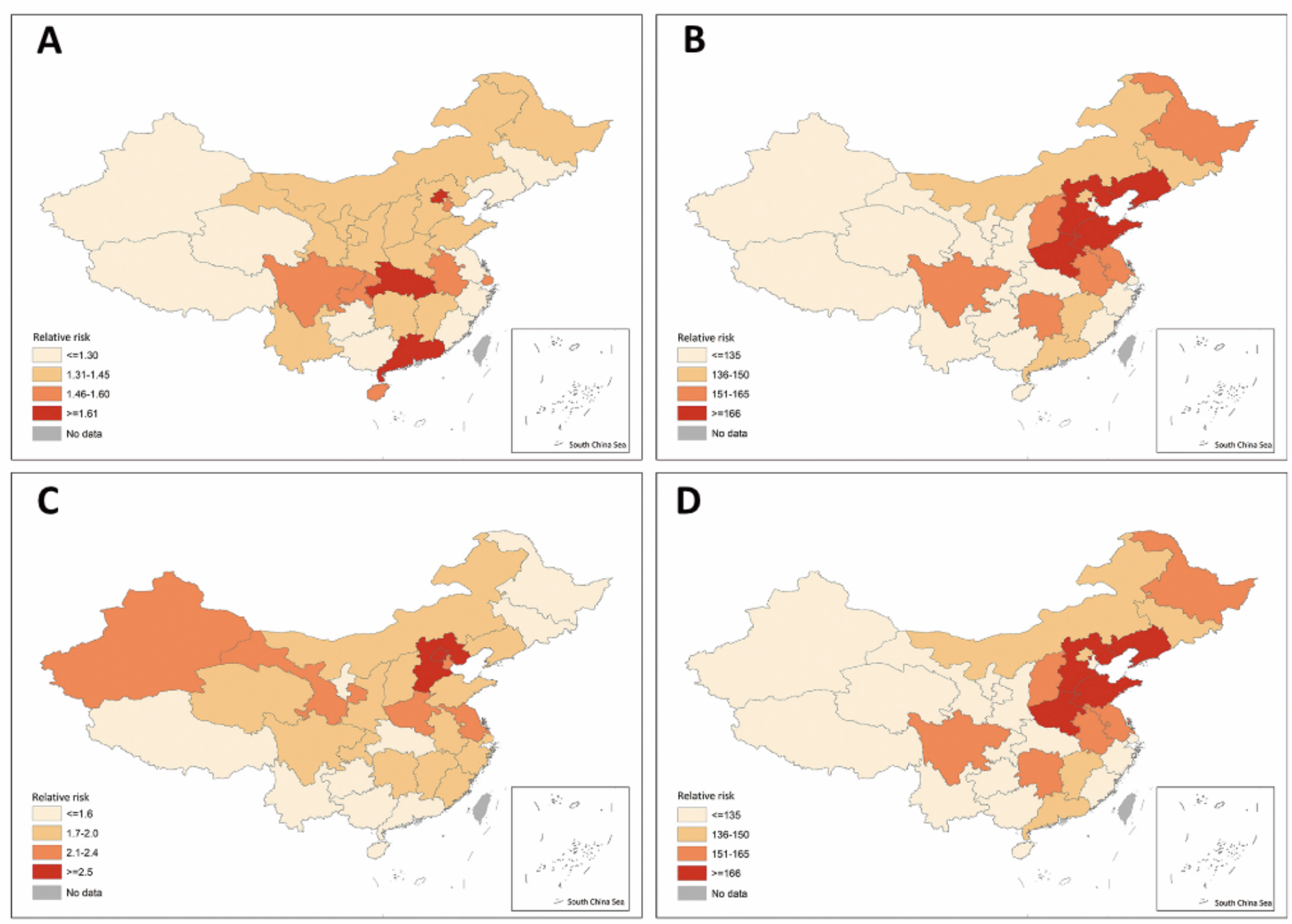

\section{Figure 2}

Immediate relative change in search index at different exposure period (A) December 31 2019, the estimated start of the first Covid-19 wave. (B) 18 January 182020 (official announcement of human-to-human transmission) to Jan 25 January 2020 (shortly after the lockdown and the estimated peak of daily search index in the initial Covid-19 wave). (C) Outbreak in Beijing starting on June 11 2020. (D) Outbreak in Shijiazhuang starting on January 32021 . Specific point estimate for relative change and the corresponding $95 \% \mathrm{Cls}$ are provided in the supplemental materials.

\section{Supplementary Files}

This is a list of supplementary files associated with this preprint. Click to download.

- STROBEchecklistv4combined.docx

- Supplementarymaterials.docx

- Figs1.pdf 